\title{
Socializing Engagement: From Words to Action
}

Kim M. Thompson, Guest Editor

Keywords: disability; diversity; inclusion

Publication Type: editorial

\section{Editorial}

As a part of The International Journal of Information, Diversity, \& Inclusion's (IJIDI) ongoing examination of facets of diversity and inclusion, this special issue focuses on Engaging Disability. Throughout this editorial process, the authors, reviewers, and I have had many opportunities to read blogs, articles, and news pieces, and have conversations about the wording used when discussing disability and inclusion. One example would be differences between person-first wording ("people with disabilities;" "individuals with mental illnesses") and disability first or broad group wording, i.e., "disabled individuals;" "wheel-chair users". Arguments for personfirst wording tend to center on ideas of the person being more important than the disability, that is, the disability is only a feature of the whole person. "A person with hearing impairment" underscores that, first and foremost, we are talking about a person and then, added on to that person, is the descriptor of a hearing limitation.

On the other hand, disability-first wording, that is, "a disabled person," can be used to emphasize that it is societal norms that disable someone by focusing too strongly on normative physical, intellectual, and social commonalities rather than the physical or cognitive variations each person brings to the table. However, the same phrase-"disabled people"-can be interpreted differently in other contexts, making "disabled" synonymous to flawed or incapable, which is far from the original intent. In some languages, translations of "disability" may mean defect, incompetence, inaptitude, unfitness, impotence, deformity, powerlessness, invalidity, or mutilation.

In terms of linguistic norms, there is no one-size-fits-all terminology in this area of engagement, be it scholarship or professional practice. As a result, in this issue you will see some variation in how the wording is used, based on a combination of author and reviewer preferences. I truly hope that the contexts set in each article will explain the wording used throughout and will be viewed as reflective of the diversity of approaches to the subject of engaging disability.

Since the call for papers for this special issue was distributed in October 2018, we have seen other journals in the field, such as Library Trends and The Journal of Academic Librarianship, publish excellent special issues and articles related to disability and inclusion. We have seen calls for book chapters, conference papers, symposia, funding applications, and other scholarly and professional communication and publications that focus on disability and inclusion. Disability and inclusion are hot topics right now in the field of library and information science, and it is wonderful to see energy flowing in this direction.

Often disability is one item on an ever-growing list of what it means to be diverse. What is

The International Journal of Information, Diversity, \& Inclusion, 4(1), 2020

ISSN 2574-3430, https://jps.library.utoronto.ca/index.php/ijidi

DOI: $10.33137 /$ ijidi.v4i1.33251 
considered diverse varies widely based on the context. In Australia, diversity is commonly spoken of in terms of gender, ethnic background or Aboriginal heritage. In China, diversity is often discussed in terms of the urban or rural places of origin or generational diversity (e.g., born before or after the One-Child Policy). Elsewhere, a diverse hire might be working to bring someone in from overseas or someone with a different religious background than one that is common in the region. Disability is unique insomuch as it is a diversity characteristic that could easily be the focus of diversity anywhere. According to the World Bank (2019), around one billion, or 15.6 percent of the world population aged 15 years and older, live with a disability; and this number is growing. Individuals with disabilities are a minority group found in every nation, every city, every community. This brings to mind the questions of differences between being "diverse" and being "representative." No two individuals in any setting will be identical. Not even if they are born in the same era, belong to the same race, gender, and religion, experience the same trauma, go through the same training, or have the same lifestyle or family setting. Each of us is diverse in many, many ways. Intellectually and socially, the unlimited ways of diversity are far too complex for humans to manage; hence, we social-type and group people based on physical, cultural, or historical similarities and differences: Indigenous Peoples, Blacks, Asians, the disabled, LGBTQIA+, the elderly, protected veterans, and so forth. Individuals within these groups, however, may or may not identify with the social type and may or may not feel representative of it. Providing specialized services for children with autism in a public library may not meet the needs of all disabled children. However, opening quiet storytime services designed to meet the needs of both autistic children and other children who prefer quiet storytime provides an opportunity for interaction and engagement without the need for anyone to label themselves in order enjoy library programming.

When considering what is meant by inclusion, an interesting comparison arises in the idea of inclusions in geological terms. Inclusions, or included fragments, add character to a stone. The inclusions are older than the host rock and come from the interior. The cover of this issue shows an inclusion of a volcanic rock. The inclusion is what makes this photograph interesting, beautiful, and engaging. How like social inclusion this is! This makes me reflect on what IJIDI Editor-in-Chief Keren Dali and I were contemplating when we subtitled this issue: social science perspectives on information and inclusion. The papers selected for this issue incorporate data, perspectives, opinions, and/or methods related to social engagement of disability through information and inclusion.

The first two articles come from Lynne C. Howarth's work related to her Exploring Pathways to Memory study. The opening article, "Narrative, Objects, and the Construction of the Self," provides an overview of the literature related to memory and personal narrative and leads to the second article, "Dementia Friendly Memory Institutions: Designing a Future for Remembering," wherein Howarth reviews dementia-friendly initiatives within the framework of disability rights.

Mirah J. Dow, Brady D. Lund, and William K. Douthit's article, "Investigating the Link between Unemployment and Disability," offers a linguistic discourse analysis of job ads in the field, demonstrating how attention to the wording of job ads can make a difference in who applies for the position. As employers pay more attention to diversity and inclusion at the workplace, research such as Dow, Lund and Douthit's can provide hiring groups with support needed for inclusive and accessible employment services.

The fourth full article for this issue is Brady C. Cross's "Library Computer Workstations for Inclusive College Student Populations." Cross provides an introduction to basic physical

The International Journal of Information, Diversity, \& Inclusion, 4(1), 2020

ISSN 2574-3430, jps.library.utoronto.ca/index.php/ijidi/index

DOI: $10.33137 /$ ijidi.v4i1.33251 
technology needs for accessible academic libraries, wrapped in a discussion of the need to consider inclusion and accessibility from a social constructivist point of view. As with the geological inclusion conceptualization, differences in the make-up of the academic community provide authenticity to the academic education experience. Physical and cognitive variations and universal design for learning make the work of an information professional and the experience of the information seeker interesting, creative, and engaging.

The special section of this issue starts off with Mary Beth Riedner, Tysha Shay, and Kayla Kuni's "Serving a Forgotten Population." This opinion piece suggests the ways in which libraries can combat some of the social isolation felt by many people living with dementia and Alzheimer's. They outline ideas for staff training, educational partnerships, special collections, and several programs that might be used to provide a more inclusive environment for engaging disability.

Shanna Hollich's autoethnographical "What It Means for a Disabled Librarian to 'Pass'” challenges normative social typing and explores the idea of "passing" as someone without disabilities in order to avoid the social stigma and the accompanying reduction of advantages received by people who do not identify as disabled. She discusses how decisions to pass as typically able might mean that an individual does not receive accommodations that could provide an equitable workload or needed public services; she shows that sometimes, it is a trade-off that individuals choose in order to avoid labeling and bias.

Michelle Green's report from the field about “Inclusive Library Service to Individuals with Mental Illnesses and Disorders" examines the literature for ideas to create inclusive and engaging library services to individuals with mental health conditions. She highlights what libraries are doing right, and what we can learn from each other through professional and research publications about programming and services.

The final article for this issue is "Creating an Authentic Experience" by Rachel Sarah Osolen and Lean Brochu. This article reports the need for more standards and innovative methods for audio translation of comics. The authors walk us through the ways in which audio production of comics differs from text-only audio production, and outline methods for better a translation of comics for the visually impaired.

I thank the authors for the interesting and diverse perspectives they lend to this issue, the reviewers for their time and expertise in helping shape the articles for publication, and the fabulous behind the scenes work by the IJIDI production staff, and hope the articles will be useful for teaching, practice, and further research related to engaging disability.

\section{References}

World Bank. (2019). Disability inclusion. Retrieved from https://www.worldbank.org/en/topic/disability

Kim M. Thompson (kthompso@mailbox.sc.edu) is Associate Dean for Academic Affairs and Associate Professor at the University of South Carolina, College of Information and

The International Journal of Information, Diversity, \& Inclusion, 4(1), 2020

ISSN 2574-3430, jps.library.utoronto.ca/index.php/ijidi/index

DOI: 10.33137/ijidi.v4i1.33251 
Communications. Her research focuses on the relationship between information access and social inclusion, using critical and qualitative methods to examine conceptualizations of digital inclusion, information access, and information poverty. Some of her current projects include analysis of inclusive/exclusive language in library job ads in Australian and United States contexts, engaging disability in the workplace, and considerations of how to set diversity and inclusion more deeply into the Library and Information Science curriculum. Kim is on the Editorial Boards of The International Journal of Information, Diversity, \& Inclusion; The Library Quarterly; Human Behaviors and Emerging Technologies; and Collection and Curation. 